\title{
The intracellular milieu of Parkinson's disease patient brain cells modulates alpha-synuclein protein aggregation
}

\author{
Nadja Gustavsson ${ }^{1}$, Ekaterina Savchenko ${ }^{2}$, Oxana Klementieva ${ }^{1 *}$ and Laurent Roybon ${ }^{2 *}$
}

\begin{abstract}
Recent studies suggest that brain cell type specific intracellular environments may play important roles in the generation of structurally different protein aggregates that define neurodegenerative diseases. Using human induced pluripotent stem cells (hiPSC) and biochemical and vibrational spectroscopy techniques, we studied whether Parkinson's disease (PD) patient genomes could modulate alpha-synuclein (aSYN) protein aggregates formation. We found increased $\beta$-sheets and aggregated aSYN in PD patient hiPSC-derived midbrain cells, compared to controls. Importantly, we discovered that aSYN protein aggregation is modulated by patient brain cells' intracellular milieus at the primary nucleation phase. Additionally, we found changes in the formation of aSYN fibrils when employing cellular extracts from familial PD compared to idiopathic PD, in a Thioflavin T-based fluorescence assay. The data suggest that changes in cellular milieu induced by patient genomes trigger structural changes of aSYN potentially leading to the formation of strains having different structures, properties and seeding propensities.
\end{abstract}

Keywords: Parkinson's disease, Protein aggregation, Alpha-synuclein, Cellular environment, Human iPSCs, Midbrain spheroids

\section{Introduction}

Protein aggregation is one of the major cellular hallmarks of neurodegenerative diseases (ND). Parkinson's disease (PD), dementia with Lewy bodies and multiple system atrophy define alpha-synucleinopathies, a group of ND characterized by intracellular aggregation of alpha-synuclein $(\mathrm{aSYN})$ protein [1]. Recent studies suggest that the intracellular environment of specific brain cells (neurons and oligodendrocytes) [2] and post-translational modifications [3], may play important roles in the generation of structurally different protein strains that define ND. However, there is no data that indicates if and how

\footnotetext{
*Correspondence: oxana.klementieva@med.lu.se; laurent.roybon@med.lu.se ${ }^{1}$ Medical Microspectroscopy, Department of Experimental Medical Science, Lund University, Lund, Sweden

2 Stem Cell Laboratory for CNS Disease Modelling, Department of Experimental Medical Science, BMC D10, Lund University, Lund, Sweden
}

patient-specific brain cells' intracellular milieus modulate protein aggregation.

Here, we studied changes in intracellular environment of PD patients' brain cells and how they modulate aSYN protein aggregation, using human induced pluripotent stem cells (hiPSC) and biochemical methods combined with infrared spectroscopy technique. Notably, we performed a Thioflavin $\mathrm{T}$ (ThT)-based fluorescence assay to examine the effect of patient genome-induced changes in brain cells intracellular milieu on aggregation of recombinant p.A53T aSYN monomers.

\section{Case presentation}

Parkinson's disease patient brain tissue is only available post-mortem when protein aggregation is advanced and adaptive processes are at play $[4,5]$. To examine early changes in aSYN protein levels and aggregation, we generated midbrain spheroids from PD patients and healthy original author(s) and the source, provide a link to the Creative Commons licence, and indicate if changes were made. The images or other third party material in this article are included in the article's Creative Commons licence, unless indicated otherwise in a credit line to the material. If material is not included in the article's Creative Commons licence and your intended use is not permitted by statutory regulation or exceeds the permitted use, you will need to obtain permission directly from the copyright holder. To view a copy of this licence, visit http://creativecommons.org/licenses/by/4.0/. The Creative Commons Public Domain Dedication waiver (http://creativecommons.org/publicdomain/zero/1.0/) applies to the data made available in this article, unless otherwise stated in a credit line to the data. 
controls' hiPSC using a well-established methodology [6] (Fig. 1a, b). Patient iPSC-derived spheroids are the closest models to human brain parenchyma [7]. Midbrain regionalized spheroids are composed in majority of astroglia positive for glial fibrillary acidic protein (GFAP) and dopaminergic neurons co-expressing the enzyme tyrosine hydroxylase $(\mathrm{TH})$ and the transcription factor FOXA2 (Fig. 1b) [6, 8]. Western blot analysis revealed significant increased levels of total aSYN in PD midbrain spheroids generated from glucocerebrosidase $(G B A)$ gene variants and synuclein alpha $(S N C A)$ locus multiplication cases, compared to controls (Fig. 1c). Dot blot analysis using OC antibody specifically recognizing fibrillar forms of amyloid $[9,10]$ and Fourier transform infrared microspectroscopy ( $\mu$ FTIR) measurements revealed increased fibrillar aSYN content and $\beta$-sheets in PD midbrain spheroids compared to controls, respectively (Fig. 1c, d).

It has been shown that changes in lipid composition present in familial glucocerebrosidase (GBA) variant forms of PD correlate with changes in aSYN aggregation [11]. Moreover, recent work suggests that changes in lipid oxidation measured by $\mu$ FTIR correlate with protein aggregation in cellular models of Alzheimer's disease [12]. $\mu$ FTIR analysis of the midbrain spheroids allowed us to further evaluate changes in lipid composition, oxidation, and lipid chain length. We found that while the amount of cellular lipids was decreased in PD midbrain spheroids, variation in their oxidation and chain length was dependent on the cells' genome (Fig. 1e, f). These data suggested that changes in lipids may fluctuate in different forms of PD, which prompted us to examine the effect of intracellular milieu on aSYN protein aggregation.

We examined aggregation of recombinant p.A53T aSYN protein monomers in intracellular environment using a ThT-based fluorescence assay. Interestingly, we found decreased ThT fluorescence for samples containing PD hiPSC-derived midbrain spheroids extracts, compared to controls (Fig. 1g). Notably, there was a lower level of ThT-based fluorescence when employing extracts from familial PD hiPSC-derived midbrain spheroids compared to idiopathic PD ones (Fig. 1g). This finding was counterintuitive since previous work showed acceleration in the reaction of recombinant aSYN fibril formation after the addition of purified lipid extracts that are most abundant in PD GBA variant cells [11] or aSYN seeds generated using protein misfolding cyclic amplification [13].

\section{Discussion and conclusions}

Our work is the first to demonstrate that changes in intracellular environment induced by patient genomes are important for aSYN aggregation. Indeed, the cellular lysate of PD patient iPSC-derived brain cells, which also includes membrane components, was capable to modulate aggregation of recombinant p.A53T aSYN monomers. ThT fluorescence was low when aSYN aggregation was allowed to form in the presence of PD extracts. This result was unexpected because increased ThT fluorescence peaks more rapidly when employing two-component systems [11, 13]. We hypothesize that protein interactors present in the PD intracellular milieu reduce ThT binding sites availability [14] or alter the amyloid structure of the formed fibrils. Alternatively, the protein interactors could potentiate the formation of small oligomers having great seeding propensities.

Given the fact that iPSCs have properties similar to embryonic stem cells [15], and that through differentiation they give rise to brain cell types with characteristics of young cells [16], we propose that our data are akin to mechanisms of PD likely occurring early in the life of

\footnotetext{
(See figure on next page.)

Fig. 1 a Table summarizing the hiPSC lines employed in the study. b Immunohistochemistry performed on 75-day old hiPSC-derived midbrain spheroids revealed abundance of TH/FOXA2-positive dopaminergic neurons. c Western blot analysis of RIPA extracts revealed an increase of $14 \mathrm{kDa}$ aSYN level in the SNCA and GBA spheroids. Western blot analysis was performed using antibody specific to aSYN. Data were normalized to the level of actin and presented as mean $\pm S D ; N=2$ patients; one line per patient; ${ }^{*} p<0.05$. Statistical analysis was performed by comparing control, SNCA and GBA using one-way ANOVA followed by Tukey's post hoc test; ${ }^{* *} p<0.01$ and ${ }^{*} p<0.05$. $\mathbf{d}$ Dot blot analysis revealed increase of aSYN fibrillar content. Dot blot analysis was performed using OC antibody specific to amyloid fibrils. Data are normalized to the control and presented as mean $\pm \mathrm{SD} ; \mathrm{N}=2$ patients; one line per patient; ${ }^{*} \mathrm{p}<0.05$. Statistical analysis was performed using a two-tailed t-test. e $\mu \mathrm{FTIR}$ analysis further revealed changes in molecular structures in the spheroids models of synucleinopathies. Bright field image of spheroid deposited on $\mathrm{CaF}_{2}$. Black line indicates the area of $\mu \mathrm{FTIR}$ analysis. Red-green-blue maps are infrared images at specific frequencies used for structural analysis. $\mathbf{f}$ Box diagrams show $\mu F T I R$ analysis of $\beta$-sheet structural content, total lipids measured as area ratio of lipids between $2800-3000 \mathrm{~cm}^{-1}$ and amide I (1600-1700 $\left.\mathrm{cm}^{-1}\right)$; lipid oxidation measured as an area ratio of peaks centered at $1740 \mathrm{~cm}^{-1}$ and amide I (1600-1700 $\left.\mathrm{cm}^{-1}\right)$; and lipid chain length measured as a ratio between peaks at $2854 \mathrm{~cm}^{-1}$ and $2874 \mathrm{~cm}^{-1}$, within healthy, SNCA multiplication, Idiopathic PD and GBA midbrain spheroids. Box diagrams show mean (represented by squares), median line, interquartile range from lowest to highest, and outliers (shown as lozenges). Statistical analysis was performed by comparing all groups using one-way ANOVA followed by Bonferroni post hoc test; ${ }^{* *} p<0.001$. g PD midbrain spheroids cellular milieus trigger aggregation of aSYN by stimulating primary nucleation of aSYN. The kinetics of $10 \mu \mathrm{M}$ recombinant p.A53T aSYN aggregation alone and in the presence of extracts from midbrain spheroids $(50 \mathrm{ng} / \mathrm{\mu L}$ ) was monitored by ThT fluorescence in $10 \mathrm{mM}$ MES pH 5.5 buffer under quiescent conditions at $37^{\circ} \mathrm{C}$. Results are presented as mean $\pm \mathrm{SD}, \mathrm{N}=2$ patients; one line per patient
} 


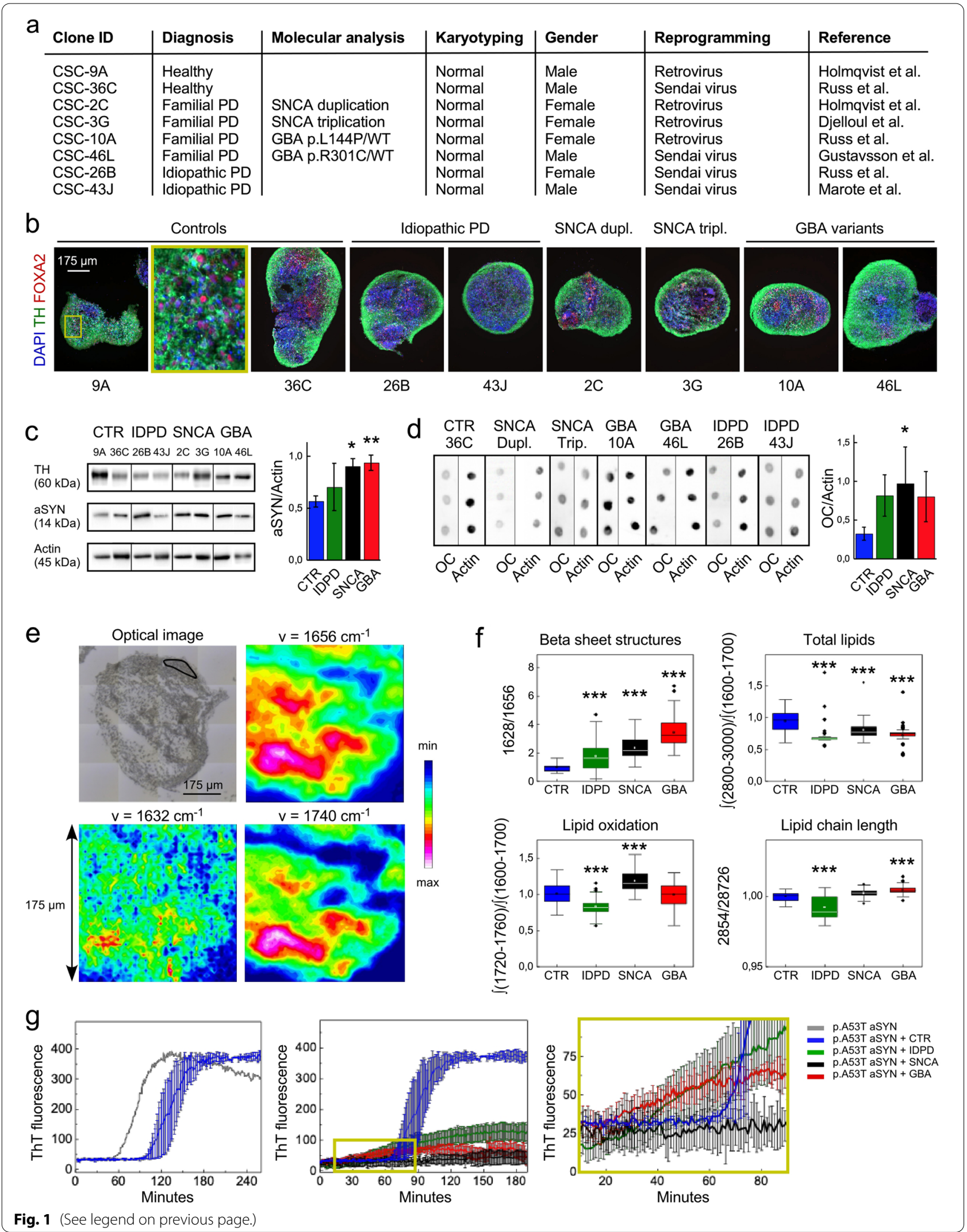


the patient. The data obtained using iPSCs further suggest that the pathological changes identified in idiopathic PD cases may have a (epi)genetic pathological process underlying.

Future efforts should focus on defining what cellular components modulate the structure and properties of aSYN protein aggregates. Few studies have identified aSYN binding partners $[17,18]$; however, it remains to be determined which ones actively contribute to the structure and properties of the aSYN assemblies generated early in life in patient brain cells. Examining similarities and differences in structures and properties of aSYN fibrillar strains that form in different familial forms of PD [GBA, SNCA and other gene variants], idiopathic PD, and other synucleinopathies [19], would allow enhanced stratification of patients towards personalized treatment(s). Ultimately, therapeutic strategies should focus into restoring normal cellular networks and pathways altered in the disease that trigger the formation of toxic aSYN assemblies. We further propose $\mu$ FTIR and ThT-based fluorescence assays as diagnostic tools to confirm PD pathology, monitor therapeutic responses, and to measure protein aggregation in the intracellular milieu of hiPSC-derived midbrain spheroids.

\section{Methods}

\section{Human induced pluripotent stem cell lines}

The generation of hiPSCs lines CSC-9A, CSC-36C, CSC2-C, CSC-3G, CSC10A, CSC46L, CSC26B and CSC43J has been previously reported [17, 20-23].

\section{Generation of midbrain spheroids containing FOXA2+/ $\mathrm{TH}+$ neurons}

To differentiate the hiPSCs into midbrain spheroids containing dopaminergic neurons, a previously established protocol was employed [6]. Briefly, hiPSCs were detached from feeders with dispase II and seeded in ultra-low attachment flasks in WiCell media supplemented with $10 \mu \mathrm{M}$ of ROCK inhibitor Y27632 and $20 \mathrm{ng} / \mathrm{mL}$ of FGF2 (Thermo Fisher Scientific). The following day, the medium was changed to neural induction medium (NIM) composed of advanced DMEM/ F12, 2 mML-glutamine, 1\% NEAA, 1\% N2 supplement, $1 \% \mathrm{P} / \mathrm{S}$ (Thermo Fisher Scientific), and supplemented with $0.1 \mu \mathrm{M}$ LDN, $10 \mu \mathrm{M}$ SB431542, $200 \mathrm{ng} / \mathrm{mL}$ SHH-C, $1 \mu \mathrm{M}$ SAG and $0.8 \mu \mathrm{M}$ CHIR (Sigma-Aldrich, SML1046). The medium was replaced every other day. On day 6, SB and SHH-C (Thermo Fisher Scientific, PMC8031) were removed from the medium and SAG concentration was increased to $2 \mu \mathrm{M}$; on day $10, \mathrm{LDN}$ was removed. From day 12 onwards, the cells were grown in NIM supplemented with $100 \mathrm{ng} / \mathrm{mL}$ FGF8 (Thermo Fisher Scientific, PHG0184), $2 \mu \mathrm{M}$ SAG, 10 ng/mL BDNF (Peprotech,
450-02-250) and $200 \mu \mathrm{M}$ ascorbic acid (AA) (SigmaAldrich, A4403). From day 22, the medium was replaced with neural differentiation medium (NDM) containing Neurobasal media with $2 \mathrm{mML}$-glutamine, 1\% NEAA, $1 \% \mathrm{~N} 2$ supplement, $1 \% \mathrm{~B} 27$ without vitamin $\mathrm{A}, 1 \% \mathrm{P} / \mathrm{S}$, supplemented with $100 \mathrm{ng} / \mathrm{mL}$ FGF8 and $2 \mu \mathrm{M}$ SAG, $10 \mathrm{ng} / \mathrm{mL}$ BDNF, $10 \mathrm{ng} / \mathrm{mL}$ GDNF (R\&D systems, 212GD/CF), $200 \mu \mathrm{M}$ AA (Sigma-Aldrich, A4403), $500 \mu \mathrm{M}$ db-cAMP (Sigma-Aldrich, D0627) and $1 \mathrm{ng} / \mathrm{mL}$ TGF (Peprotech, 100-36E). From day 30 onwards, FGF8 and SAG were removed from the medium and $50 \mu \mathrm{M}$ DA (Sigma-Aldrich, H850) was added to promote pigmentation of the spheroids.

\section{Immunostaining and image acquisition}

For immunohistochemistry, spheroids were fixed in $4 \%$ paraformaldehyde (PFA) and snap-frozen in liquid nitrogen prior to be sectioned into $20 \mu \mathrm{m}$ thick sections using a cryostat (Leica Microsystems GmH, Wetzlar Germany). Samples were then stored at $-80{ }^{\circ} \mathrm{C}$ for immunohistochemical staining. Frozen sections were air-dried for $1 \mathrm{~h}$, then blocked for $1 \mathrm{~h}$ at RT in PBS containing 10\% donkey serum and $0.1 \%$ PBS-Tween 20. Primary antibodiesgoat anti-FOXA2 (Santa-Cruz, sc6554, 1:250) and mouse anti-TH (Millipore, MAB318, 1:500), were diluted in blocking solution and sections were incubated overnight at $4{ }^{\circ} \mathrm{C}$. Sections were rinsed and incubated with appropriate Alexa-fluor 488- and 555-conjugated secondary antibodies in PBS (1:400, Thermo Fisher Scientific), for $1 \mathrm{~h}$ at room temperature (RT) in the dark. Additionally, cell nuclei were stained with DAPI (1:10,000; SigmaAldrich). All fluorescent images were acquired using an LRI-Olympus IX-73 epifluorescence microscope.

\section{Western and dot blot analysis}

Spheroids aged 75 days in vitro (DIV) were homogenized in RIPA buffer (ThermoFisher Scientific, Sweden) complemented with Halt Protease Inhibitor and Halt Phosphatase Inhibitor Cocktails (ThermoFisher Scientific, Sweden). After a short centrifugation step to remove cell debris, the supernatant was collected, and protein concentrations estimated using the $\mathrm{BCA}$ protein assay kit (ThermoFisher Scientific, Sweden, \#23225). For Western blot, samples were heated at $70{ }^{\circ} \mathrm{C}$ for $10 \mathrm{~min}$ in tricine SDS sample buffer $2 \times$ Novex (\#LC1676). Samples were loaded onto 10-20\% Tricine SDS-PAGE gels (Sigma-Aldrich, Sweden) and run at $125 \mathrm{~V}$ in Tricine SDS Running Buffer (ThermoFisher Scientific, Sweden, \#LC167523225). Gels were then fixed in $20 \%$ ethanol for $5 \mathrm{~min}$, followed by protein transfer to polyvinylidene difluoride (PVDF) membranes (Sigma-Aldrich, Sweden, \#IB24002). Membranes were incubated in $0.4 \%$ PFA for $20 \mathrm{~min}$ at RT 
and washed in PBS-T. Membranes were blocked using a 5\% skim milk (Sigma-Aldrich) in PBS-Tween 20 (PBST) solution, and incubated overnight with primary antibodies diluted in blocking solution, at $4{ }^{\circ} \mathrm{C}$. Primary antibodies: mouse anti-actin (Sigma-Aldrich, A5441, 1:5000); aSYN (BioLegend, \#848301, 1:1000), and TH (Millipore, MAB318, 1:1000). Dot blot samples were deposited directly onto PVDF membranes with OC antibody (Sigma-Aldrich, Sweden, \#AB 2286, 1:5000), that targets amyloid fibrils. The blots were incubated with primary antibodies overnight. Next day, membranes were washed and incubated with HRP-conjugated secondary antibodies (1:1000; R\&D Systems) for $1 \mathrm{~h}$. Blots were revealed using Pierce Enhanced ChemoLuminescence solution and imaged using The Ultimate Western Blot Imaging System Azure c600 (AH diagnostics AB, Sweden). Quantification was performed using ImageJ.

\section{Fourier Transform Infrared microspectroscopy and data analysis}

$\mu$ FTIR analyses were performed for spheroids aged 75 DIV. Briefly, $16 \mu \mathrm{m}$ cryosectioned spheroid slices were mounted on $1 \mathrm{~mm}$ thick $\mathrm{CaF}_{2}$ spectrophotometric windows (Eksma Optics, Lithuania) and dried under nitrogen flow. For reproducibility, infrared spectra were taken from areas of the spheroid with maximum TH expression. Spectra were recorded at RT using a Hyperion 3000 IR microscope (Bruker Scientific Instruments, Billerica, MA, USA) coupled to a Tensor 27 with MCT (mercury cadmium telluride) detector. The measuring was performed using a range of $900-4000 \mathrm{~cm}^{-1}$, with a $4 \mathrm{~cm}^{-1}$ resolution, using 500 co-added scans. The background spectra were collected from a clean area of the same $\mathrm{CaF}_{2}$ window. OPUS software (Bruker) was used for atmospheric compensation; Orange software (University of Ljubljana [24]) was used to analyze FTIR spectra. To unmask the band positions and to eliminate the baseline contribution, we used second order derivation of the spectra using Savitsky-Golay of 3rd polynomial order 7 with 11 smoothing points [25]. For $\mu$ FTIR analysis, we used IR bands in the Amide I region $\left(1630-1615 \mathrm{~cm}^{-1}\right)$, which is ascribed to the $\beta$-sheet structures. The $2000-3000 \mathrm{~cm}^{-1}$ region is defined by lipids, and the $1720-1760 \mathrm{~cm}^{-1}$ by lipid oxidation [26-29]. For lipidation, we used the ratio between peak areas of $2800-3000 \mathrm{~cm}^{-1}$ and Amide I (1600-1700 $\mathrm{cm}^{-1}$ ), for lipid oxidation, we used the ratio between the peak centered around $1740 \mathrm{~cm}^{-1}$ and Amide I (1600-1700 $\left.\mathrm{cm}^{-1}\right)$, and for quantification of $\beta$-sheet structural content we used IR intensity at $1628 \mathrm{~cm}^{-1}$, normalized to total proteins to Amide I max at $1656 \mathrm{~cm}^{-1}$.

\section{Thioflavin T-based fluorescence assay}

Recombinant aSYN was produced as previously described [30]. To follow the fibrillation process, $10 \mu \mathrm{M}$ aSYN was added to 96-well non-binding PEGylated plates and supplemented with $5 \mathrm{mM}$ ThT in MES buffer with $\mathrm{pH}$ 5.5. RIPA extracts were added to the wells to reach a final amount of $5 \mu \mathrm{g}$ of total proteins per well. The plates were incubated at $37^{\circ} \mathrm{C}$ up to $72 \mathrm{~h}$ in a plate reader (FluoStar Omega or FluoStar Galaxy, BMG Labtech, Offenburg, Germany) under quiescent conditions (excitation filter $440 \mathrm{~nm}$ and emission filter $480 \mathrm{~nm})$.

\section{Statistical analysis}

Statistical analysis was carried out using OriginPro2019 software. The FTIR and Dot Blot data was normally distributed and was calculated as means \pm standard deviations (SD). Statistical significance was determined using one-way ANOVA, followed by Bonferroni or Tukey's post hoc tests.

\section{Abbreviations}

ND: Neurodegenerative diseases; PD: Parkinson's disease; aSYN: Alpha-synuclein; hiPSC: Human induced pluripotent stem cells; ThT: Thioflavin T; $\mu F T I R$.

Fourier transform infrared microspectroscopy; GBA: Glucocerebrosidase; SNCA: Synuclein alpha; GFAP: Glial fibrillary acidic protein; TH:Tyrosine hydroxylase.

\section{Acknowledgements}

The authors would like to thank Prof. E. Sparr at Lund University for providing recombinant P.A53T aSYN. The authors are part of the strategic research area MultiPark and the Lund Stem Cell Center, at Lund University, Lund, Sweden.

\section{Authors' contributions}

NG: Performed experiments, interpreted data, edited manuscript; ES: Generated midbrain spheroids, interpreted data, edited manuscript; OK: Performed measurements, interpreted data, wrote manuscript; LR: Designed study, interpreted data; wrote manuscript. All authors read and approved the final manuscript.

\section{Funding}

Open access funding provided by Lund University. This work was supported by grants from the Michael J. Fox Foundation (Grant ID 15068), the Swedish Research Council (Grant ID 2015-03684 and 2017-01539) and Åhlén-stiftelsen (Grant ID 203057).

\section{Availability of data and materials}

The datasets used and/or analysed during the current study available from the corresponding author on reasonable request.

\section{Declarations}

Ethics approval and consent to participate

All procedures were conducted in accordance with national and European Union directives. The patient biopsies utilized to generate the hiPSCs were obtained with informed consent and after ethical committee approval at the Parkinson Institute in Milan, Italy: Ethics Committee "Milano Area C" (http:// comitatoeticoareac.ospedaleniguarda.it/) and registered under the Number: 370-062015. The permit for reprogramming was delivered by the Swedish work environment authority to L.R. and registered under the Number 20200-3211 


\section{Competing interests}

The authors declare that they have no competing interests.

Received: 2 August 2021 Accepted: 6 September 2021 Published online: 16 September 2021

\section{References}

1. Goedert M, Jakes R, Spillantini MG (2017) The synucleinopathies: twenty years on. J Parkinsons Dis 7(s1):S51-S69

2. Peng C, Gathagan RJ, Covell DJ, Medellin C, Stieber A, Robinson JL, Zhang B, Pitkin RM, Olufemi MF, Luk KC, Trojanowski JQ, Lee VM (2018) Cellular milieu imparts distinct pathological alpha-synuclein strains in alphasynucleinopathies. Nature 557(7706):558-563

3. Arakhamia T, Lee CE, Carlomagno Y, Duong DM, Kundinger SR, Wang K, Williams D, DeTure M, Dickson DW, Cook CN, Seyfried NT, Petrucelli L, Fitzpatrick AWP (2020) Posttranslational modifications mediate the structural diversity of tauopathy strains. Cell 180(4):633-644

4. Kouli A, Camacho M, Allinson K, Williams-Gray CH (2020) Neuroinflammation and protein pathology in Parkinson's disease dementia. Acta Neuropathol Commun 8(1):211

5. Miller KM, Mercado NM, Sortwell CE (2021) Synucleinopathy-associated pathogenesis in Parkinson's disease and the potential for brain-derived neurotrophic factor. NPJ Parkinsons Dis 7(1):35

6. Chumarina M, Russ K, Azevedo C, Heuer A, Pihl M, Collin A, Frostner EA, Elmer E, Hyttel P, Cappelletti G, Zini M, Goldwurm S, Roybon L (2019) Cellular alterations identified in pluripotent stem cell-derived midbrain spheroids generated from a female patient with progressive external ophthalmoplegia and parkinsonism who carries a novel variation (p.Q811R) in the POLG1 gene. Acta Neuropathol Commun 7(1):208

7. Pasca AM, Sloan SA, Clarke LE, Tian Y, Makinson CD, Huber N, Kim CH, Park JY, O'Rourke NA, Nguyen KD, Smith SJ, Huguenard JR, Geschwind DH, Barres BA, Pasca SP (2015) Functional cortical neurons and astrocytes from human pluripotent stem cells in 3D culture. Nat Methods 12(7):671-678

8. Jo J, Xiao Y, Sun AX, Cukuroglu E, Tran HD, Goke J, Tan ZY, Saw TY, Tan CP, Lokman H, Lee Y, Kim D, Ko HS, Kim SO, Park JH, Cho NJ, Hyde TM, Kleinman JE, Shin JH, Weinberger DR, Tan EK, Je HS, Ng HH (2016) Midbrainlike organoids from human pluripotent stem cells contain functional dopaminergic and neuromelanin-producing neurons. Cell Stem Cell 19(2):248-257

9. Huang YR, Xie XX, Ji M, Yu XL, Zhu J, Zhang LX, Liu XG, Wei C, Li G, Liu RT (2019) Naturally occurring autoantibodies against alpha-synuclein rescues memory and motor deficits and attenuates alpha-synuclein pathology in mouse model of Parkinson's disease. Neurobiol Dis 124:202-217

10. Kayed R, Head E, Sarsoza F, Saing T, Cotman CW, Necula M, Margol L, Wu J, Breydo L, Thompson JL, Rasool S, Gurlo T, Butler P, Glabe CG (2007) Fibril specific, conformation dependent antibodies recognize a generic epitope common to amyloid fibrils and fibrillar oligomers that is absent in prefibrillar oligomers. Mol Neurodegener 2:18

11. Galvagnion C, Cerri S, Schapira AHV, Blandini F, Di Monte DA (2020) Sphingolipid changes in Parkinson L444P GBA mutation fibroblasts promote a-synuclein aggregation. bioRxiv 2020.11.09.375048

12. Gustavsson N, Paulus A, Martinsson I, Engdahl A, Medjoubi K, Klementiev K, Somogyi A, Deierborg T, Borondics F, Gouras GK, Klementieva O (2021) Correlative optical photothermal infrared and X-ray fluorescence for chemical imaging of trace elements and relevant molecular structures directly in neurons. Light Sci Appl 10(1):151

13. Jung BC, Lim YJ, Bae EJ, Lee JS, Choi MS, Lee MK, Lee HJ, Kim YS, Lee SJ (2017) Amplification of distinct alpha-synuclein fibril conformers through protein misfolding cyclic amplification. Exp Mol Med 49(4):e314

14. Groenning $M$, Olsen L, van de Weert M, Flink JM, Frokjaer S, Jorgensen FS (2007) Study on the binding of Thioflavin T to beta-sheet-rich and nonbeta-sheet cavities. J Struct Biol 158(3):358-369
15. Takahashi K, Tanabe K, Ohnuki M, Narita M, Ichisaka T, Tomoda K, Yamanaka S (2007) Induction of pluripotent stem cells from adult human fibroblasts by defined factors. Cell 131(5):861-872

16. Mertens J, Reid D, Lau S, Kim Y, Gage FH (2018) Aging in a dish: PSCderived and directly induced neurons for studying brain aging and agerelated neurodegenerative diseases. Annu Rev Genet 52:271-293

17. Russ K, Teku G, Bousset L, Redeker V, Piel S, Savchenko E, Pomeshchik Y, Savistchenko J, Stummann TC, Azevedo C, Collin A, Goldwurm S, Fog K, Elmer E, Vihinen M, Melki R, Roybon L (2021) TNF-alpha and alphasynuclein fibrils differently regulate human astrocyte immune reactivity and impair mitochondrial respiration. Cell Rep 34(12):108895

18. Shrivastava AN, Redeker V, Fritz N, Pieri L, Almeida LG, Spolidoro M, Liebmann T, Bousset L, Renner M, Lena C, Aperia A, Melki R, Triller A (2015) alpha-synuclein assemblies sequester neuronal alpha3-Na+/K+-ATPase and impair Na+ gradient. EMBO J 34(19):2408-2423

19. Surguchov A (2020) Analysis of protein conformational strains: a key for new diagnostic methods of human diseases. Int J Mol Sci 21(8):2801

20. Djelloul M, Holmqvist S, Boza-Serrano A, Azevedo C, Yeung MS, Goldwurm S, Frisen J, Deierborg T, Roybon L (2015) Alpha-synuclein expression in the oligodendrocyte lineage: an in vitro and in vivo study using rodent and human models. Stem Cell Rep 5(2):174-184

21. Gustavsson N, Marote A, Pomeshchik Y, Russ K, Azevedo C, Chumarina M, Goldwurm S, Collin A, Pinto L, Salgado AJ, Klementieva O, Roybon L, Savchenko E (2019) Generation of an induced pluripotent stem cell line (CSC-46) from a patient with Parkinson's disease carrying a novel p.R301C mutation in the GBA gene. Stem Cell Res 34:101373

22. Holmqvist S, Lehtonen S, Chumarina M, Puttonen KA, Azevedo C, Lebedeva O, Ruponen M, Oksanen M, Djelloul M, Collin A, Goldwurm S, Meyer M, Lagarkova M, Kiselev S, Koistinaho J, Roybon L (2016) Creation of a library of induced pluripotent stem cells from Parkinsonian patients. NPJ Parkinsons Dis 2:16009

23. Marote A, PomeshchikY, Goldwurm S, Collin A, Lamas NJ, Pinto L, Salgado AJ, Roybon L (2018) Generation of an integration-free induced pluripotent stem cell line (CSC-43) from a patient with sporadic Parkinson's disease. Stem Cell Res 27:82-85

24. Demsar J, Curk T, Erjavec A, Gorup C, Hocevar T, Milutinovic M, Mozina M, Polajnar M, Toplak M, Staric A, Stajdohar M, Umek L, Zagar L, Zbontar J, Zitnik M, Zupan B (2013) Orange: data mining toolbox in python. J Mach Learn Res 14:2349

25. Kong J, Yu S (2007) Fourier transform infrared spectroscopic analysis of protein secondary structures. Acta Biochim Biophys Sin (Shanghai) 39(8):549-559

26. Oleszko A, Olsztynska-Janus S, Walski T, Grzeszczuk-Kuc K, Bujok J, Galecka K, Czerski A, Witkiewicz W, Komorowska M (2015) Application of FTIR-ATR spectroscopy to determine the extent of lipid peroxidation in plasma during haemodialysis. Biomed Res Int 2015:245607

27. Cerf E, Sarroukh R, Tamamizu-Kato S, Breydo L, Derclaye S, Dufrene YF, Narayanaswami V, Goormaghtigh E, Ruysschaert JM, Raussens V (2009) Antiparallel beta-sheet: a signature structure of the oligomeric amyloid beta-peptide. Biochem J 421(3):415-423

28. Petibois C, Deleris G (2008) Analysis and monitoring of oxidative stress in exercise and training by FTIR spectrometry. Int I Sports Physiol Perform 3(2):119-130

29. Petibois C, Deleris G (2004) Oxidative stress effects on erythrocytes determined by FT-IR spectrometry. Analyst 129(10):912-916

30. Grey M, Linse S, Nilsson H, Brundin P, Sparr E (2011) Membrane interaction of alpha-synuclein in different aggregation states. J Parkinsons Dis 1(4):359-371

\section{Publisher's Note}

Springer Nature remains neutral with regard to jurisdictional claims in published maps and institutional affiliations. 